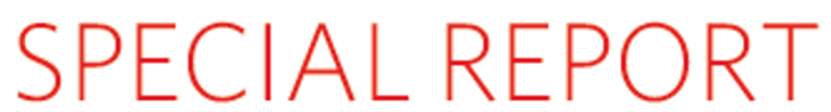

\title{
What happens after the water recedes?
}

\author{
New Orleans universities are still struggling to recover from the ravages of Hurricane Katrina. \\ Heidi Ledford examines how researchers at one leading institution are coping.
}

$\longrightarrow$ n a grim day last September, a tencar convoy of researchers drove into the putrid waters of downtown New Orleans. Scientists fanned out across the Tulane University health-sciences campus, salvaging computers and research samples from buildings flooded in the aftermath of Hurricane Katrina.

Today, the university campus buzzes with activity of a different sort. Undergraduate classes resumed in January, with $93 \%$ of students returning for the spring semester. Research experiments are again under way. And preliminary numbers suggest that Tulane earned $\$ 133$ million in sponsored research last year - a mere 3\% drop from the previous year.

Tulane has emerged relatively unscathed compared with other institutions in New Orleans (see 'Around New Orleans', opposite). Yet even at Tulane, Katrina has left a permanent mark in the form oflow morale, lost equipment and laid-off faculty members.

On 29 August 2005, Katrina separated Tulane's two campuses by more than just geography. Floodwaters barely reached the stately buildings of the university's historic uptown campus for undergraduates. Science departments there were up and running after a few rough months of limited electricity and minor

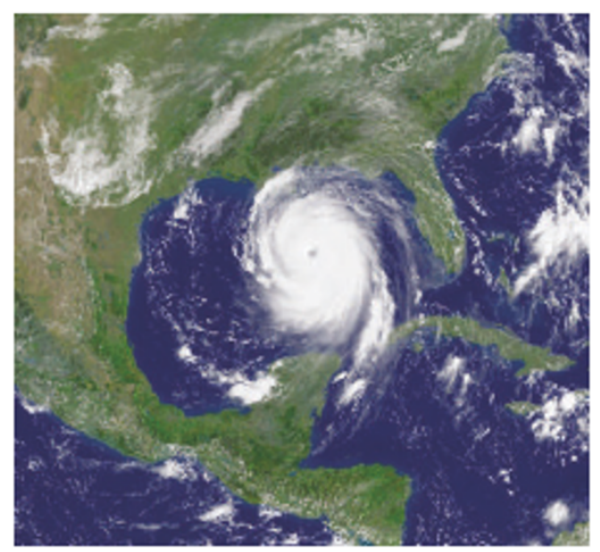

As Hurricane Katrina headed for New Orleans, few were anticipating the flood it left in its wake.

repairs. "On the undergraduate campus, you'd be hard pressed to find any evidence that there was a storm," says Robert Garry of the department of microbiology and immunology. ${ }^{\alpha}$ But other parts...well, it's not so good."

These other parts of Tulane are located downtown, nearly 5 kilometres away, on the health-sciences campus. There, the waters rose to 2 to 3 metres, flooding electricity supplies and maintenance rooms on the lower floors. Some research labs began operating again as early as November, but others didn't reopen until January (see 'Winds of change: 5 three stories from Tulane's faculty', below). \& Even then conditions were difficult: in the J. Bennett Johnston Health and Environmental Research Building, the first health-sciences building to reopen, some researchers were left warming their hands over Bunsen burners when temperature controls failed last winter.

Back in August last year, electricity losses also doomed many experiments. It is safe to say that no one working in the biomedical sciences at Tulane will ever again take refrigeration for granted. Power failures and warm temperatures destroyed stem-cell lines, tissue cultures and antibodies, some of which were the products of years of specialized work. Only some samples were saved through emergency rescue efforts.

"We lost in excess of $\$ 100$ million of biological assets," says John Clements, dean of research at the medical school. "But we also saved $\$ 100$ million of biological assets." Researchers credit the National Institutes of Health and the National Science Foundation with providing resources for recouping their losses, and Tulane itself has dedicated $\$ 20$ million to research grants to be awarded over the next two years.

Others lost far more - their jobs. The university, having sustained property damage

\section{Winds of change: three stories from Tulane's faculty}

\section{Tyler Curiel: \\ Leaving \\ After the storm, \\ theflood, \\ helicopter \\ rescues amid \\ gunfire and a}

four-month exile in Colorado, cancer researcher Tyler Curiel has made a decision he says is "very painful". He is about to leave New Orleans for good.

In September, he will become the director of the University of Texas Health Science Center in San Antonio. Curiel says that in New Orleans, the poor conditions of his lab facilities and of the rest of the city are hindering his research too much. His Tulanelab still lacks emergency power for its freezers, and hecan't find enough candidates to take part in clinical trials because the university hospital has so few patients. "What worked before Katrina does not necessarily work postKatrina," Curiel says. "And my kind of research just does not workhere."

\section{Prescott Deininger: Staying}

The associate director of Tulane's cancer centre knows he was lucky. His house did not flood. His lab was one of the first at the university to reopen. His lab members all returned. Now Prescott Deininger is back to writing papers and applying for grants.

But his job has changed a little. He has had to go from lab to lab talking to investigators to find out what it will take to convince them to stay at Tulane. It's hard for him not to take it personally when faculty members leave. "It tears the guts out of me," he says.

\section{Cesar Fermin: Recovering} In December 2005, Cesar Fermin was a tenured faculty member at the Tulane medical school, studying hair cells of the inner ear. The next month, he was a handyman at Fermin's
HandyWorks, repairing damaged homes. After 15 years as a professor of pathology, Fermin was laid off in

December. Unable to leave New Orleans for financial reasons, he decided to pick up the tools in his garage to earn a living.

Fermin soon began to miss the intellectual challenge of academia. "When you're going to put 40 sheets of Sheetrock [plasterboard] on a house," he says, "you start on Monday and on Wednesday you're still hanging Sheetrock." He is applying for academic positions outside New Orleans. 
